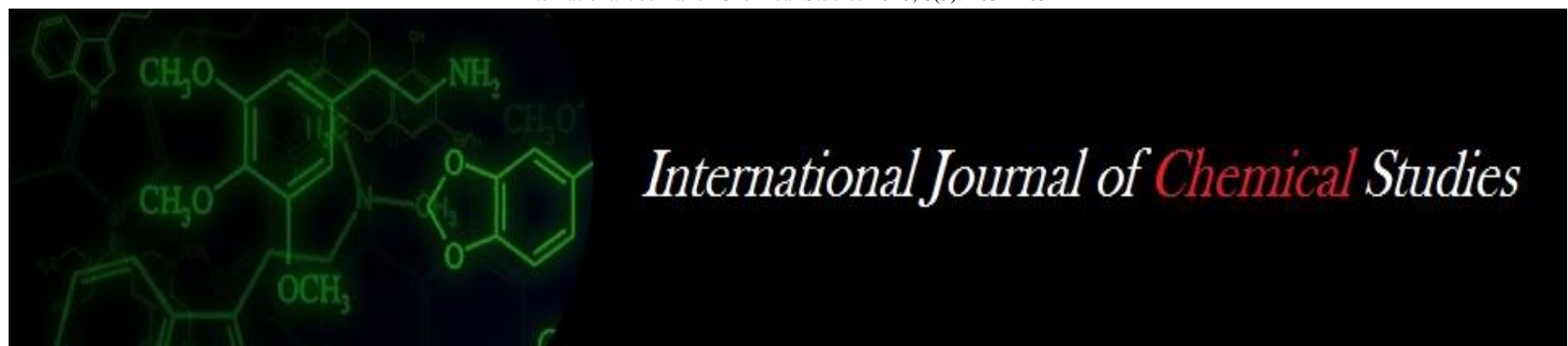

P-ISSN: 2349-8528

E-ISSN: 2321-4902

www.chemijournal.com

IJCS 2020; 8(3): 1051-1054

(C) 2020 IJCS

Received: 01-03-2020

Accepted: 03-04-2020

Sudeepa Kumari Jha

BAU, Kanke, Ranchi,

Jharkhand, India

Rabindra Prasad

BAU, Kanke, Ranchi,

Jharkhand, India
Corresponding Author: Sudeepa Kumari Jha

BAU, Kanke, Ranchi, Jharkhand, India

\section{Influence of weather factors on incidence of yellow stem borer in aromatic rice under agro- climatic condition of Jharkhand}

\author{
Sudeepa Kumari Jha and Rabindra Prasad
}

DOI: https://doi.org/10.22271/chemi.2020.v8.i3n.9337

\begin{abstract}
Field experiment was conducted to study the influence of weather factors on incidence of yellow stem borer, Scirophaga incertula under agro-climatic condition of Jharkhand. It was revealed that incidence of YSB started after one or two week of transplanting and it caused dead heart in vegetative stage and white ear head in reproductive stage of the crop. Dead heart had significant correlation with maximum temperature while white ear head had negative effect.
\end{abstract}

Keywords: Yellow stem borer, dead heart, white ear head

\section{Introduction}

Rice (Oryza sativa L.) is the world's second most important cereal crop feeding about $50 \%$ of the world population and provides $19 \%$ of the global calories intake (IRRI, 2014) ${ }^{[1]}$. Rice is the world's second most important cereal crop, feeding about $50 \%$ of the world population and provides single largest food source for the poor throughout Asia. Aromatic rice is rice with natural chemical compounds which give it a distinctive aroma. Two prominent aromatic cultivars of rice in the world market include Basmati (India and Pakistan) and Khao Dawk Mali or Jasmine (Thailand). Basmati cultivar has specific grain characteristics and traditionally grown in Himalayan foot hills of Indian sub-continent. The export values and quantities of Basmati rice are accounted for almost all rice exports from India (Napasintuwong, 2012) ${ }^{[5]}$. Besides the basmati types which get high price in international markets, the country also abounds with several indigenous aromatic cultivars and landraces grown in pockets of different states. Almost every state has its own collection of aromatic rice that performs well in native areas (Rani and Krishnaiah, 2001) ${ }^{[7]}$. The quality traits like aroma, fluffiness and taste fetch higher price in the market but these are susceptible to pest and diseases attack and generally low yielders, hence, farmers are unable to make their cultivation a profitable venture. In a particular area insect pest fauna attacking aromatic rice are the same as those prevalent on non-aromatic rice (Singh et al., 2010) ${ }^{[9]}$ but the extent of attack of these pest are bound to enhance due to aromatic nature of this group of rice.

The attack of insect-pest fauna is one of the major constraints in obtaining the yield potential from the newly evolved varieties and the instances of crop failure due to outbreaks have been reported worldwide (Reddy, 2013) ${ }^{[8]}$. Soren (2013) ${ }^{[10]}$ reported that in Ranchi region of Jharkhand, fourteen insect pest species were found associated with rice in different stages of crop growth in overlapping fashion. Among them only six species i.e. yellow stem borer, gall midge, hispa, leaf folder, green leaf hopper, case worm and gundhi bug could be considered attacked as major insect pests and remaining eight species as minor pests. These insect pests were responsible for 20-35\% grain yield loss of rice in Jharkhand (Prasad et al., 2006 and Krshnaiah et al., 2008) ${ }^{[6,3]}$. Among the different insects associated with rice, the yellow stem borer, Scirpophaga incertulas (Walker) is one of the most destructive and widely distributed from tropics to temperate regions (Torii, 1967) infesting from seedling to maturity stages. The damage in the early stage of the crops results in dead hearts and at a later stage in white ear head. It is rather difficult to find a direct cause and effect relationship between any single factor and pest activity because the impact of weather factors on pest is usually compounded. For developing weather-based pest forecasting models, the information on the relationship 
between the incidence of insect pests and weather factors is needed. Thus, the present study was undertaken to find out the effect of factors on the incidence of yellow stem borer.

\section{Materials and Methods}

Study of influence of weather factors on incidence of yellow stem borer in aromatic rice (var. Birsa Vikash Sugandh-1) was carried out at Rice Research Farm of Birsa Agricultural University Kanke, Ranchi during Kharif season of 2018 and 2019. Twenty days old seedling transplanted to main plot on $23^{\text {rd }}$ and $24^{\text {th }}$ July (30 SMW) with spacing of $20 \mathrm{~cm}$ row to row and $15 \mathrm{~cm}$ plant to plant. Ten hills were randomly selected in each plot of three replications and tagged. Total number of total tillers, panicles, dead heart (DH) and white ear head (WEH) per ten hills (tagged) were counted at weekly intervals starting from one week after transplanting to till harvesting and correlated with weekly meteorological data Table 01 (maximum temperature, minimum temperature, morning relative humidity, evening relative humidity, rainfall and sunshine hours recorded from the meteorological observatory of the Department of Agro-meteorology and Environmental Science of BAU, Kanke, Ranchi. Multiple regression equations were established to find out change in dependent variable with unit change in independent variable. The coefficient of determination $\left(\mathrm{R}^{2}\right)$ was also calculated for multiple regression equation to interpret proportion of variable in the dependent variable that is predicted from the independent variable so that risk bearing capacity of model may be determined.

$\mathrm{DH}(\%)=\frac{\text { Total no. of dead heart }(\mathrm{DH}) \text { in } 10 \text { hills }}{\text { Total no. of tillers }(\mathrm{DH}+\text { healthy tillers)in } 10 \text { hills }} \times 100$

$\mathrm{WEH}(\%)=\frac{\text { Total no.of WEH in } 10 \text { hills }}{\text { Total no.of panicles }(\mathrm{WEH}+\text { healthy panicles }) \text { in } 10 \text { hills }} \times 100$

\section{Results and Discussion}

The data presented in Table 2 revealed that incidence of $\mathrm{DH}$ was observed from 31 and 32 SMW with density 0.36 and 1.48 per cent and reached on peak level at 36 and 37 SMW with 7.15 and 6.18 per cent $\mathrm{DH}$, respectively in the year 2018 and 2019, respectively. After attainment of peak level of the incidence of $\mathrm{DH}$ it was observed to be declined continuously and disappear from the field after 42 and 41 SMW in the first and second year of the experiment, respectively. Pooled mean of the two year data revealed that incidence of DH was started from $31 \mathrm{SMW}$ with 0.18 per cent $\mathrm{DH}$ and reached at its peak level on 37 SMW with 6.48 per cent DH. The incidence of WEH was firstly recorded at 36 SMW with 0.68 and 0.48 per cent density in the year 2018 and 2019, respectively after that it increased continuously up to the end of cropping season i.e. 44 SMW with 8.15 and 7.64 per cent WEH, respectively. Pooled mean of the two years data revealed that incidence of WEH was started from 36 SMW with 0.58 per cent WEH and increased continuously up to 44 SMW with 7.92 per cent WEH in the present investigation. This experimental finding is supported by the results of Varma et al. (2000) ${ }^{[12]}$ reported three peak periods of activity viz; July, August and September. After that Varma (2004) [11] noticed that maximum incidence of YSB was recorded during September and October. Mishra et al. (2012) reported that YSB exhibiting their peak activity in the month of September. Population build up of stem borer infestation was found maximum during August-September with 6.82-7.62\% dead heart and 7.56 to $8.14 \% \mathrm{WEH}$ on second fortnight of October (Kalita et al., 2015) ${ }^{[2]}$.
The data presented in the Table 03 revealed that during both the years $(2018,2019)$ of the experiment, DH had significant correlation with maximum temperature while evening humidity and rainfall had significant correlation only during the first year of experiment. During both the years of the experiment, DH had positive correlation with maximum temperature and minimum temperature while negative correlation with the evening humidity. But correlation of $\mathrm{DH}$ with rainfall, morning humidity and sunshine hours varied from first to second year of the experiment. In the year 2018 DH had positive correlation $(\mathrm{r}=0.719)$ with rainfall while in next year correlation was negative $(-0.188)$. While DH had negative and positive correltion with morning humidity $(\mathrm{r}=-$ $0.226,0.422)$ and sunshine hours $(r=-0.010,0.056)$ in the first and second year of experiment, respectively. Pooled mean of two years data revealed that $\mathrm{DH}$ had positive correlation with all the weather parameters i.e. maximum temperature $(r=0.730)$, minimum temperature $(r=0.522)$, morning humidity $(\mathrm{r}=0.095)$, rainfall $(\mathrm{r}=0.460)$ and sunshine hours $(\mathrm{r}=0.051)$ except evening humidity $(\mathrm{r}=$ $0.137)$. Among these parameters significant correlation was found only with maximum temperature.

In the first year of the experiment WEH had only significant correlation with rainfall while in the second year, it had significant correlation with maximum and minimum temperature. During both the years of the experiment WEH had positive correlation with morning ( $\mathrm{r}=0.396,0.122)$ and evening humidity $(\mathrm{r}=0.265,0.137)$ and sunshine hours $(\mathrm{r}=$ $0.615,0.347)$ while negative correlation with maximum $(\mathrm{r}=-$ $0.359,-0.821)$ and minimum temperature $(r=-0.662,-0.760)$. Correlation between WEH and rainfall ( $\mathrm{r}=-0.861,0.092)$ was negative and positive for the first and second year of the experiments, respectively. Pooled mean of two year data revealed that WEH had significant correlation with maximum and minimum temperature. The correlation was positive with morning $(r=0.371)$ and evening humidity $(r=0.233)$ and sunshine hours $(\mathrm{r}=0.603)$ while negative correlation with maximum $(r=-0.738)$ and minimum temperature $(r=-0.843)$ and rainfall $(\mathrm{r}=-0.401)$. Present finding is partially supported by the results of Bhatnagar and Saxena (1999) they found that rainfall $(r=0.521)$ and sunshine hours $(r=0.609)$ had significant and positive correlation while minimum temperature $(\mathrm{r}=-0.807)$ and minimum relative humidity (0.782 ) had significant and negative correlation with the population of YSB. Rehman (2002) reported that low temperature, high relative humidity and rainfall could to be responsible for YSB outbreak. Patel and Singh (2017) found that weather conditions, particularly the amount of rainfall during the cropping period starting from June to October could be able to influence the YSB incidence to a great extent. The sunshine hour is also a major factor, which along with rainfall, influences the severity of yellow stem borer on rice.

The multiple regression equation between DH per cent as dependent variable and weather parameters as independent variables revealed that unit change in weather parameters i.e. maximum temperature, minimum temperature, morning relative humidity, evening relative humidity, rainfall and sunshine hours were responsible for $(2.54,1.14$ and 3.16), ($1.46,-0.01$ and -1.36$),(0.58,1.17$ and -0.92$),(0.27,-0.57$ and - 0.86), (0.04, -0.02 and 0.03) and (- 0.06, - 0.07 and - 0.02) unit change in DH per cent during the first, second year of the experiment and their pooled mean of 2018 and 2019, respectively. Unit change in weather parameters i.e. maximum temperature, minimum temperature, morning relative humidity, evening relative humidity, rainfall and 
sunshine hours was responsible for $(0.78,-2.46$ and -0.87$)$, ($0.97,0.95$ and -0.30$),(1.05,1.81$ and -0.06$),(1.82,-0.80$ and 0.90), (-0.06, 0.01 and 0.01) and (-0.11, 0.14 and 0.11) unit change in WEH per cent during the first, second year of the experiment and their pooled mean, respectively.

The value of coefficient of determination $\left(\mathrm{R}^{2}\right)$ were 0.8012 , 0.7783 and 0.7640 for the year 2018, 2019 and their pooled mean, respectively, which indicated that $80.12,77.83$ and 76.40 per cent variation in the dependent variable (DH \%) can be predicted by the independent variable while $19.88,22.17$ and 23.60, respectively remains unexplained. The value of $\mathrm{R}^{2}$ was $0.9617,0.9478$ and 0.8912 for the year 2018, 2019 and their pooled mean, respectively, which indicated that 96.17 , 94.78 and 89.12 per cent variation in the dependent variable (WEH \%) can be predicted by the independent variable while $3.83,5.22$ and 10.88 per cent respectively, remains unexplained.

Table 1: Weekly meteorological data during the period of investigation

\begin{tabular}{|c|c|c|c|c|c|c|c|c|c|c|c|c|c|c|c|c|c|c|}
\hline \multirow{3}{*}{ SMW } & \multicolumn{6}{|c|}{ Temperature $\left({ }^{\circ} \mathrm{C}\right)$} & \multicolumn{6}{|c|}{ Relative humidity (\%) } & \multirow{2}{*}{\multicolumn{3}{|c|}{ Rainfall (m }} & \multirow{2}{*}{\multicolumn{3}{|c|}{ Sunshine (hrs) }} \\
\hline & \multicolumn{3}{|c|}{ Max } & \multicolumn{3}{|c|}{ Min } & \multicolumn{3}{|c|}{ 07:00 AM } & \multicolumn{3}{|c|}{ 02:00 PM } & & & & & & \\
\hline & 2018 & 2019 & $\begin{array}{l}\text { Pooled } \\
\text { Mean }\end{array}$ & 18 & 2019 & $\begin{array}{l}\text { Pooled } \\
\text { Mean }\end{array}$ & 20 & 2019 & $\begin{array}{l}\text { Pooled } \\
\text { Mean }\end{array}$ & 2018 & 2019 & $\begin{array}{l}\text { Pooled } \\
\text { Mean }\end{array}$ & 2018 & 2019 & $\begin{array}{l}\text { Pooled } \\
\text { Mean }\end{array}$ & 3 & 9 & \\
\hline 31 & 27.30 & 30.40 & 2885 & 20.10 & .40 & 21.75 & 5.60 & 85.00 & 85.30 & U & U & & 8.80 & 20 & & 2.10 & 14.40 & \\
\hline 32 & 27.30 & 30.00 & .65 & .30 & 23.10 & .20 & 85.90 & 86.00 & & & & & 7.60 & & & 25. & 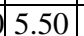 & \\
\hline 33 & 28.00 & 29.60 & & 0 & 22.30 & & 5.70 & 86.00 & & & & & & & & & & \\
\hline 34 & 29.60 & 29.90 & & & 0 & & 0 & 8 & & & & & & & & & & \\
\hline 35 & 29.10 & 30.60 & 29. & 0 & 23.60 & & 84.60 & 86.00 & & & & & & & & & & \\
\hline 36 & 7.00 & 30.10 & 2 & 18.80 & 22.20 & & 84.90 & 86.00 & & & & & & & & & 20 & \\
\hline 37 & 29.60 & 30.70 & 30 . & 19.90 & 23.70 & & 85.70 & 87.00 & & & 3.00 & & & & & 56 & 90 & \\
\hline 38 & 29.10 & 31 & & 10 & 22.90 & & 5.60 & 87. & & & & & & & & & & \\
\hline 39 & 29.40 & 28.80 & & & 21.30 & & 5.10 & 00 & & & 00 & & 0 & & & & 10 & \\
\hline 40 & 27.90 & 28.90 & & 18.30 & 21.70 & & 85.00 & 86.00 & & & .00 & & 00 & & & 61 & 48.50 & 4.85 \\
\hline 41 & 26.40 & 28.30 & 27. & 16.50 & 21.20 & & 83.70 & 86.00 & & 69 & 68.00 & & 2.00 & 60 & & 39.20 & 39.00 & 9.10 \\
\hline 42 & 25.90 & 29.10 & 27.50 & 15.20 & 20.70 & & 86.90 & 86.00 & & & .00 & & 00 & & & & 60 & 7.55 \\
\hline 43 & 6.50 & 26.20 & 26. & & 17.80 & & 87.00 & 88.00 & & & & & & & & & 2.70 & \\
\hline 44 & 27.90 & 26.30 & 27.1 & 17.90 & 14.30 & 0.1 & 87.00 & 87.00 & 87.00 & 68.40 & 69.00 & 68.7 & 0.00 & 0.00 & 0.00 & 52.60 & 57.90 & 55.25 \\
\hline
\end{tabular}

Table 2: Incidence of yellow stem borer in aromatic rice

\begin{tabular}{|c|c|c|c|c|c|c|}
\hline \multirow{3}{*}{ SMW } & \multicolumn{7}{|c|}{ YSB } \\
\cline { 2 - 7 } & \multicolumn{3}{|c|}{ DH \% } & \multicolumn{2}{c|}{ WEH \% } \\
\cline { 2 - 7 } & $\mathbf{2 0 1 8}$ & $\mathbf{2 0 1 9}$ & Pooled Mean & $\mathbf{2 0 1 8}$ & $\mathbf{2 0 1 9}$ & Pooled Mean \\
\hline 31 & 0.36 & --- & 0.18 & --- & --- & --- \\
\hline 32 & 1.62 & 1.48 & 1.55 & --- & --- & --- \\
\hline 33 & 3.16 & 2.38 & 2.77 & --- & --- & --- \\
\hline 34 & 5.13 & 3.39 & 4.26 & --- & --- & --- \\
\hline 35 & 6.22 & 4.32 & 5.27 & --- & --- & --- \\
\hline 36 & 7.15 & 5.43 & 6.29 & 0.68 & 0.48 & 0.58 \\
\hline 37 & 6.78 & 6.18 & 6.48 & 2.28 & 1.15 & 1.72 \\
\hline 38 & 4.12 & 5.23 & 4.68 & 5.00 & 2.53 & 3.77 \\
\hline 39 & 2.11 & 4.21 & 3.16 & 5.76 & 4.37 & 5.07 \\
\hline 40 & 1.28 & 1.30 & 1.29 & 6.22 & 5.05 & 5.64 \\
\hline 41 & 0.76 & 0.40 & 0.58 & 6.88 & 6.23 & 6.56 \\
\hline 42 & 0.24 & --- & 0.12 & 7.25 & 6.90 & 7.08 \\
\hline 43 & --- & --- & --- & 7.89 & 7.23 & 7.56 \\
\hline 44 & --- & --- & --- & 8.15 & 7.68 & 7.92 \\
\hline
\end{tabular}

Table 3: Correlation coefficient between weather parameters and incidence of insect pests of aromatic rice

\begin{tabular}{|c|c|c|c|c|c|c|c|c|c|c|c|c|c|c|c|c|c|c|}
\hline \multirow{3}{*}{$\begin{array}{c}\text { Insect } \\
\text { pest }\end{array}$} & \multicolumn{6}{|c|}{ Temperature $\left({ }^{\circ} \mathrm{C}\right)$} & \multicolumn{6}{|c|}{ Relative humidity (\%) } & \multirow{2}{*}{\multicolumn{3}{|c|}{$\begin{array}{c}\text { Rainfall } \\
(\mathbf{m m})\end{array}$}} & \multirow{2}{*}{\multicolumn{3}{|c|}{$\begin{array}{c}\text { Sunshine } \\
\text { (hrs) }\end{array}$}} \\
\hline & \multicolumn{3}{|c|}{ Max } & \multicolumn{3}{|c|}{ Min } & \multicolumn{3}{|c|}{ 07:00 AM } & \multicolumn{3}{|c|}{ 02:00 PM } & & & & & & \\
\hline & 2018 & 2019 & $\begin{array}{c}\text { Pooled } \\
\text { Mean }\end{array}$ & 2018 & 2019 & $\begin{array}{l}\text { Pooled } \\
\text { Mean }\end{array}$ & 2018 & 2019 & $\begin{array}{l}\text { Pooled } \\
\text { Mean }\end{array}$ & \begin{tabular}{|l|}
2018 \\
\end{tabular} & 2019 & $\begin{array}{l}\text { Pooled } \\
\text { Mean }\end{array}$ & 2018 & 2019 & $\begin{array}{c}\text { Pooled } \\
\text { Mean }\end{array}$ & 2018 & 2019 & $\begin{array}{c}\text { Pooled } \\
\text { Mean }\end{array}$ \\
\hline DH \% & $0.577 *$ & $0.703^{*}$ & $0.730^{* * *}$ & 0.502 & 0.478 & 0.522 & $\begin{array}{c}- \\
0.226 \\
\end{array}$ & 0.422 & 0.095 & $\begin{array}{c}- \\
0.679^{*}\end{array}$ & $\begin{array}{c}- \\
0.382 \\
\end{array}$ & -0.137 & $0.719^{* *}$ & $\mid \begin{array}{c}- \\
0.188\end{array}$ & 0.460 & $\begin{array}{c}- \\
0.010 \\
\end{array}$ & 0.056 & 0.051 \\
\hline WEH \% & -0.359 & $-\overline{-}$ & $-0.738^{*}$ & $\begin{array}{c}- \\
0.662\end{array}$ & $\begin{array}{c}- \\
0.760^{*}\end{array}$ & $-0.843 * *$ & $0.396 \mid$ & 0.122 & 0.371 & 0.265 & 0.137 & 0.233 & $-0.861 *$ & 0.092 & -0.401 & $0.615 \mid$ & 0.345 & 0.603 \\
\hline & & & & & & & $\mathrm{H}: \mathrm{D}$ & $\mathrm{ad} \mathrm{h}$ & WEH: & $\begin{array}{l}\text { t } 1 \% \\
\text { Vhite ea }\end{array}$ & Ir head, & & & & & & & \\
\hline
\end{tabular}


Table 4: Multiple regression equation between weather parameters (X) and insect pests (Y) of aromatic rice

\begin{tabular}{|c|c|c|}
\hline Insect pest & Multiple regression equation & $\begin{array}{c}\text { Coefficient of determination } \\
\left(\mathbf{R}^{2}\right)\end{array}$ \\
\hline \multicolumn{3}{|r|}{$x$} \\
\hline $\mathrm{DH} \%$ & $Y=-107.34+2.54 X_{1}-1.46 X_{2}+0.58 X_{3}+0.27 X_{4}+0.04 X_{5}-0.06 X_{6}$ & 0.8012 \\
\hline WEH \% & $Y=-206.29+0.78 X_{1}-0.97 X_{2}+1.05 X_{3}+1.82 X_{4}-0.06 X_{5}-0.11 X_{6}$ & 0.9617 \\
\hline \multicolumn{3}{|c|}{2019} \\
\hline $\mathrm{DH} \%$ & $\mathrm{Y}=-88.77+1.14 \mathrm{X}_{1}-0.01 \mathrm{X}_{2}+1.17 \mathrm{X}_{3}-0.57 \mathrm{X}_{4}-0.02 \mathrm{X}_{5}-0.07 \mathrm{X}_{6}$ & 0.7783 \\
\hline WEH \% & $Y=-51.54-2.46 \mathrm{X}_{1}+0.95 \mathrm{X}_{2}+1.81 \mathrm{X}_{3}-0.80 \mathrm{X}_{4}+0.01 \mathrm{X}_{5}+0.14 \mathrm{X}_{6}$ & 0.9478 \\
\hline \multicolumn{3}{|c|}{ Mean } \\
\hline $\mathrm{DH} \%$ & $Y=76.48+3.16 X_{1}-1.36 X_{2}-0.92 X_{3}-0.86 X_{4}+0.03 X_{5}-0.02 X_{6}$ & 0.7640 \\
\hline WEH \% & $Y=-25.94-0.87 X_{1}-0.30 X_{2}-0.06 X_{3}+0.90 X_{4}+0.01 X_{5}+0.11 X_{6}$ & 0.8912 \\
\hline \multicolumn{3}{|c|}{$\begin{array}{c}\mathrm{X}_{1}-\text { Max temp. } \mathrm{X}_{2}-\text { Min temp } \mathrm{X}_{3}-\mathrm{RH}(07: 00 \mathrm{AM}) \mathrm{X}_{4}-\mathrm{RH}(02: 00 \mathrm{PM}) \mathrm{X}_{5} \text {-Rainfall } \mathrm{X}_{6} \text {-Sunshine } \\
\text { DH: Dead heart, WEH: White ear head }\end{array}$} \\
\hline
\end{tabular}

\section{References}

1. IRRI. World Rice statistics online query facility web page. 2014.

2. Kalita, Avashte RK, Ramesh K. Effect of weather parameters on population build up of different insect pests of rice and their natural enemies. Indian Journal of Hill Farming. 2015; 28(1):69-72.

3. Krishnaiah NV, Lakshmi VJ, Pasalu IC, Katti GR, Padmavathi C. Insecticides in rice IPM past, present and future, DRR, (ICAR) Rajendranagar, Hyderabad, 2008, 146.

4. Mishra MK, Sharma RC, Singh RB, Singh RP. Monitoring of yellow stem borer, Scirpophaga incertulas Walker in rice through light and pheromone traps. Agric. and Biological Res. 2012; 28(2):135-139.

5. Napasintuwong O. Survey of Recent Innovations in Aromatic Rice. 131th EAAE Seminar Innovation for Agricultural Competitiveness and Sustainability of Rural Areas, Prague, 2012.

6. Prasad R, Sathi SK, Prasad UK. Insect pest scenario in rice ecosystem in Ranchi. Indian Journal of Entomology. 2006; 12(3):649-656.

7. Rani SN, Krishnaiah K. Current status and future prospects for improvement of aromatic rices in India, In: Specialty rices of the world: Breeding, production and marketing, Science Publishers, Inc., USA: 2001, 49-78.

8. Reddy PP. Recent advances in crop protection, 2013.

9. Singh D, Bhatnagar P, Om H, Sheokand RS. Efficacy of insecticides against stem borer, Scirophaga incertulas (Walker) and leaf folder, Cnaphalocrosis medinalis (Guenee) in Basmati rice in Punjab. Indian Journal of Entomology. 2010; 67(3):234-237.

10. Soren A. Studies on the incidence of insect pest of rice and their management. M.Sc (Ag.) thesis submitted to Depatment of Agricultural Entomology, Birsa Agricultural University, Kanke, Ranchi (Jharkhand), 2013.

11. Varma NRG, Krishnaiah K, Pasalu IC, Rao PRM. Influence of field size in management of yellow stem borer (YSB), Scirpophaga incertulas Walker through pheromone mediated mass trapping in rice. Indian J Plant Protec. 2004; 32(1):39-41.

12. Varma NRG, Krishnaiah K, Pasalu IC, Reddy DDR. Monitoring of rice yellow stem borer, Scirpophaga incertulas Walker using pheromone traps and thermal summations. Indian Journal of Plant Protec. 2000; 28(1):84-93. 